\title{
Non-dialysis dependent chronic kidney disease is associated with high total and out-of-pocket healthcare expenditures
}

\author{
Christina Small ${ }^{1}$, Holly J. Kramer ${ }^{1,2,3}$, Karen A. Griffin ${ }^{2,3}$, Kavitha Vellanki $^{2,3}$, David J. Leehey ${ }^{2,3}$, Vinod K. Bansal ${ }^{2}$
} and Talar W. Markossian ${ }^{1 *}$ (D)

\begin{abstract}
Background: Previous studies have documented the high costs of non-dialysis dependent chronic kidney disease (CKD) but out-of-pocket healthcare expenditures remain poorly explored. This study described total direct and out-of-pocket expenditures for adults with non-dialysis dependent CKD and compared expenditures with those for cancer or stroke.

Methods: This study used data from the 2011-2013 Medical Expenditure Panel Survey, a national survey of healthcare expenditures in the U.S. population. Expenditures were determined for adults with the following chronic diseases: CKD defined by 585 ICD9 codes ( $n=52)$, cancer (colon, breast or bronchus/lung) $(n=870)$, or stroke $(n=1104)$. These represent adults who were aware of their conditions or visited a healthcare provider for the condition during the study period. Generalized linear models were used to estimate the marginal effects of CKD, cancer or stroke on adjusted expenditures compared to adults without CKD, cancer or stroke $(n=72,241)$ while controlling for demographics and co-morbidities and incorporating the sample weights of the complex survey design.

Results: The mean age for group with CKD, cancer or stroke was 65.5, 66.1, and 68.2 years, respectively, while mean age for group without CKD, cancer or stroke was 47.8 years. Median values of total direct and out of pocket healthcare expenditures ranged from as high as \$12,877 (Interquartile Range [IQR] \$5031-\$19,710) and \$1439 (\$688-\$2732), respectively, with CKD, to as low as \$1189 (IQR \$196-\$4388) and \$226 (IQR \$20-\$764) in the group without CKD, cancer or stroke. After adjusting for demographics and comorbidities, the adjusted difference in total direct healthcare expenditures was $\$ 4746$ (95\% Cl \$1775-\$7718) for CKD, \$8608 (95\% Cl \$6167-\$11,049) for cancer and \$5992 (95\% Cl $\$ 4208$-\$7775) for stroke vs. group without CKD, cancer or stroke. Adjusted difference in out-of-pocket healthcare expenditures was highest for adults with CKD (\$760; 95\% Cl 0-\$1745) and was larger than difference noted for cancer ( $\$ 419 ; 95 \%$ Cl 158-679) or stroke ( $\$ 246 ; 95 \%$ Cl 87-406) relative to group without CKD, cancer or stroke.
\end{abstract}

Conclusions: Total and out of pocket health expenditures for adults with non-dialysis dependent CKD are high and may be equal to or higher than expenditures incurred by adults with cancer or stroke.

\footnotetext{
* Correspondence: tmarkossian@luc.edu

${ }^{1}$ Department of Public Health Sciences, Loyola University Chicago, $2160 \mathrm{~S}$ First Ave, Maywood, IL 60153, USA
}

Full list of author information is available at the end of the article International License (http://creativecommons.org/licenses/by/4.0/), which permits unrestricted use, distribution, and reproduction in any medium, provided you give appropriate credit to the original author(s) and the source, provide a link to the Creative Commons license, and indicate if changes were made. The Creative Commons Public Domain Dedication waiver (http://creativecommons.org/publicdomain/zero/1.0/) applies to the data made available in this article, unless otherwise stated. 


\section{Background}

More than 20 million people or approximately $10 \%$ of U.S. adults currently have non-dialysis dependent chronic kidney disease (CKD), $[1,2]$ and almost one out of every two adults aged 30-64 years is expected to develop CKD during their lifetime $[3,4]$. While dialysis dependent CKD accounts for only $0.5 \%$ of the U.S. population, fee-for service expenditures for Medicare beneficiaries with dialysis dependent CKD exceeded 30 billion dollars in 2013, or over $7 \%$ of Medicare paid claims cost [5]. Nevertheless, an escalation in healthcare expenditures associated with CKD starts prior to requirement for dialysis and treatment costs escalate as non-dialysis dependent CKD progresses [6-8].

The escalation in costs in CKD is largely due to the increasing burden of comorbidities as CKD progresses [6, 9-12], thus requiring patients with CKD to seek care from multiple providers, with an average of 10.8 physician visits per year [13]. Only cancer patients had a higher average number of annual physician visits [14]. The total number of medications among adults with CKD may also be higher than most other chronic medical conditions with one study reporting that over $60 \%$ of adults with stage 3 CKD taking 5 or more different medications daily [11]. The high total number of physician visits and medications required for CKD care drives up total direct healthcare expenditures and likely also increases out-of-pocket expenditures, creating a financial burden for patients.

While total expenditures for dialysis dependent and non-dialysis dependent CKD have been previously documented, $[5,6,15,16]$ out of pocket costs for non-dialysis dependent CKD remain poorly explored. Higher out-ofpocket cost burden can impede efforts to prevent disease progression. Previous research has shown that some patients opt to not fill prescriptions or take less than the prescribed amount due to out of pocket costs [17]. The aim of this study was to describe the total healthcare expenditures including out-of-pocket costs for non-dialysis dependent CKD and compare these expenditures with those incurred for cancer and stroke in the U.S. adult population. We selected these chronic conditions because both stroke and CKD are the costliest conditions for Part A Medicare beneficiaries, while for Part B Medicare beneficiaries, cancer and CKD are the costliest conditions [18]. We hypothesized that both direct and out-of-pocket healthcare expenditures in adults with non-dialysis dependent CKD are comparable if not higher than expenditures incurred for cancer or stroke.

\section{Methods}

\section{Study population}

This cross-sectional study described total and out-ofpocket health care expenditures for the chronic conditions: nondialysis dependent CKD, cancer, and stroke, each condition exclusively, and compared the expenditures for these chronic conditions with those incurred among the population without CKD, cancer or stroke. The study was approved by the Loyola University Medical Center Institutional Review Board. Data were obtained from the household, medical conditions and medical provider component (MPC) files of the Medical Expenditures Panel Survey (MEPS) for years 2011 to 2013. MEPS is a household survey of the noninstitutionalized civilian population and is conducted annually. The household component provides information on respondents' health status, demographic and socioeconomic characteristics, employment, access to care, and satisfaction with health care. For the MPC, a sample of medical providers are contacted to obtain information that household respondents can not accurately provide about dates of visits, diagnosis and procedure codes, charges and payments. The MEPS data are weighted to produce estimates of healthcare expenditures that are representative of the non-institutionalized civilian population.

The medical conditions file contains information describing current medical conditions reported by respondents during participant interviews. Information that cannot be accurately provided by participants is collected through telephone calls to providers. A current condition is defined as a condition linked to an event or disability day as well as any condition(s) the person is currently experiencing. These conditions are recorded by the interviewer as verbatim text and then translated into International Classification of Diseases, $9^{\text {th }}$ Edition, Clinical Modification (ICD-9-CM) codes by professional coders. To preserve confidentiality, nearly all of the diagnosis condition codes provided on this file have been collapsed to 3-digit code categories. MEPS data provide clinical classification codes (CCC) that are clinically meaningful categories that group similar conditions and are detailed in Table 1. Dialysis utilization during a given year is also collected and classified as a medical event code. Respondents reported a specific condition as being bothersome during the study period or as the reason for a medical event (hospital stay, outpatient visit, emergency room visit, home health episode, prescribed medication purchase, or medical provider visit). Therefore conditions that are undiagnosed, not bothersome during the study period, or not linked with a medical event are not ascertained in MEPS.

Respondents younger than 21 years were excluded from this study. A total of 74,452 adults aged 21 years and older participated in the MEPS study during 2011-2013. Participants were further excluded if they had received dialysis or reported more than one of the studied conditions CKD, cancer and stroke simultaneously. Our study include a total of 52 sampled persons with non-dialysis dependent CKD. A total of 1104 sampled persons had CCS codes 
Table 1 Definition of the clinical classification software (CCS) diagnosis categories in the Medical Expenditure Panel Survey

\begin{tabular}{lll}
\hline CCS diagnosis categories & ICD-9-CM diagnosis codes & Definition \\
\hline $\begin{array}{l}{ }^{a} \text { Chronic Kidney Disease (CKD) } \\
158\end{array}$ & $585,5853,5854,5855,5856,5859$ & CKD \\
Cancer & 153015311532153315341535153615371538153915902303 V1005 & Colon Cancer \\
14 & 174017411742174317441745174617481749175017592330 V103 & Breast Cancer \\
24 & 1622162316241625162816292312 V1011 & Lung Cancer \\
19 & 430431432043214329433014331143321433314338143391434043400 & Acute cerebrovascular disease \\
Stroke & 434014341434104341143494349043491436 & Transient cerebral ischemia \\
109 & 435043514352435343584359 & \\
112 & &
\end{tabular}

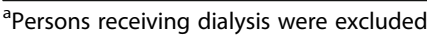

indicating stroke and 870 participants had CCS codes indicating colon, breast or bronchus/lung cancers (Table 1). Sampled persons without CKD, stroke or cancer totaled 72,241 .

\section{Healthcare expenditures}

Per-capita annual total direct health care expenditures, defined as third party (Medicare, Medicaid, private, other) and patient out-of-pocket payments for medical services were calculated. Types of medical services included inpatient, outpatient, prescription drug, dental, vision, home health, and payments for other medical equipment and services reported during the calendar years 2011-2013. Expenditure values were all calculated as year 2013 dollars. Out-of-pocket spending included self-reported payments for coinsurance and deductibles, and cash outlays for services, supplies, and other items not covered by health insurance. Out-of-pocket expenditures burden was calculated as the ratio of out-of-pocket spending to personal income and expressed as a percentage varying from 0 to 100 with high out-of-pocket spending burden as spending $10 \%$ or more of personal income on health care [19].

\section{Covariates}

The panel of this study is composed of five rounds of interviews covering two full calendar years. Demographic questions were asked during each round of interview. Demographic variables including age, height and weight and race/ethnicity were self-reported and collected by MEPS. For this study, race/ethnicity was categorized as non-Hispanic White, non-Hispanic Black, Hispanic and other. Health insurance was categorized as public, private or none. Body mass index (BMI) was calculated as weight $(\mathrm{kg})$ divided by height in $\mathrm{m}$ (squared). MEPS collected data on total family income and family size and five categories of poverty status were then defined by MEPS based on the ratio of family income to family size and composition: poor (less than 100\% to the poverty line), near poor (100\%- $125 \%$ of the poverty line), low income (125\%-less than $200 \%$ of the poverty line), middle income (200\%- less than $400 \%$ of the poverty line) and high income ( $\geq 400 \%$ of the poverty line). Self-reported perceived mental and physical health statuses were ascertained in MEPS and categorized as excellent, very good, good, fair and poor. The presence of other cooccurring physical conditions were measured as binary variables based on self-reporting a physician diagnosis of angina, arthritis, asthma, coronary heart disease, high cholesterol, diabetes, emphysema, high blood pressure, heart attack, and other heart disease.

\section{Statistical analysis}

All analyses accounted for the complex sampling design of MEPS dataset by using the sampling weight, variance estimation stratum and primary sampling unit. The Taylor-series approach was implemented to estimate standard errors for weighted survey estimates. Demographic characteristics, presence of other co-occurring physical conditions, total health care expenditures, outof-pocket spending, and out-of-pocket spending burden was presented by condition categories using descriptive statistics. In this study, none of the participants with non-dialysis dependent CKD and a relatively small number of participants with cancer or stroke, had zero expenditures. Therefore the generalized linear model (glm) was used to estimate the adjusted total health care expenditures and out-of-pocket spending by the three condition categories compared to the group without CKD, cancer or stroke while simultaneously controlling for race/ethnicity, age, health insurance, gender, poverty status and presence of other co-occurring physical conditions.. We used the gamma distribution with log-link function and presented the marginal effects and their standard errors $[20,21]$. The regression analyses did not adjust for perceived physical and mental health status and BMI due to the potential collinearity of these variables with the condition categories and other co- 
occurring physical conditions. All analyses were conducted using Stata 13 and $P<0.05$ was considered statistically significant.

\section{Results}

Table 2 demonstrates characteristics of the populations with the indicated conditions. The average age in groups with CKD, cancer, or stroke were 65.5, 66.1, and 68.2 years, respectively. Mean age in group without cancer, stroke or CKD was 47.8 years. Private insurance ranged from as low as $50.3 \%$ in the group with stroke to $65.2 \%$ in the group with CKD. Only $18.8 \%$ of the group with CKD rated their physical health as excellent or very good. In contrast, $39.7 \%$ and $25.0 \%$ of those with cancer and stroke, respectively, rated their physical health as excellent or very good. Table 3 demonstrates the prevalence of comorbidities in the three chronic condition groups, exclusively. Of the indicated conditions, the group with CKD had the highest prevalence of high cholesterol (85.0\%), high blood pressure (87.8\%) and diabetes (49.6\%).

The annual mean total healthcare expenditures ranged from as high as $\$ 12,877$ for non-dialysis dependent CKD to as low as $\$ 7428$ for the chronic condition cancer (Table 4). The annual mean out-of-pocket expenditures was also highest for the group with non-dialysis dependent CKD (\$1439; IQR \$688-\$2732), and lowest for the group with stroke (\$748; IQR \$242-\$1559). Fig. 1 shows the out-of-pocket health care expenditure burden, calculated as the ratio of out-of-pocket spending to personal income. The annual out-of-pocket health care expenditure burden for cancer and stroke were 5.1 and 5.8, respectively. However, the out-of-pocket healthcare expenditure burden for group with non-dialysis dependent

Table 2 Demographic and clinical characteristics of U.S. adults aged 21 years or older by condition categories, years 2011 -2013

\begin{tabular}{|c|c|c|c|c|}
\hline & Chronic Kidney Disease (CKD) ${ }^{\mathrm{a}}$ & Cancer $^{\mathrm{b}}$ & Stroke & No CKD, cancer or stroke ${ }^{c}$ \\
\hline Study sample, $n=74,267$ & 52 & 870 & 1104 & 72,241 \\
\hline Study population estimate over 3 year period, $N=940,337,592$ & 607,506 & $9,206,890$ & $10,520,699$ & $650,226,082$ \\
\hline Age (years) & 65.5 & 66.1 & 68.2 & 47.8 \\
\hline \multicolumn{5}{|l|}{ Race } \\
\hline Non-Hispanic White (\%) & 79.7 & 79.0 & 73.0 & 66.4 \\
\hline Non-Hispanic Black (\%) & 11.6 & 10.0 & 15.2 & 11.2 \\
\hline Hispanic (\%) & 7.4 & 8.0 & 7.8 & 14.8 \\
\hline Other (\%) & 1.3 & 3.0 & 4.0 & 7.6 \\
\hline Male (\%) & 48.7 & 15.8 & 49.1 & 48.5 \\
\hline BMI [kg/m (squared)] & 28.3 & 26.7 & 26.9 & 27.1 \\
\hline \multicolumn{5}{|l|}{ Poverty Status ${ }^{d}$} \\
\hline Poor (\%) & 9.3 & 10.9 & 19.5 & 12.1 \\
\hline Near Poor (\%) & 2.6 & 7.0 & 7.3 & 4.4 \\
\hline Low Income (\%) & 17.2 & 15.4 & 19.0 & 13.6 \\
\hline Middle Income (\%) & 32.8 & 30.6 & 30.4 & 30.3 \\
\hline High Income (\%) & 38.1 & 36.1 & 23.8 & 39.7 \\
\hline \multicolumn{5}{|l|}{ Health Insurance } \\
\hline Public (\%) & 26.8 & 32.9 & 46.5 & 17.0 \\
\hline Private (\%) & 65.2 & 65.1 & 50.3 & 67.7 \\
\hline None (\%) & 8.1 & 2.0 & 3.2 & 15.4 \\
\hline \multicolumn{5}{|l|}{ Perceived Physical Health } \\
\hline Excellent (\%) & 6.0 & 13.0 & 4.2 & 24.7 \\
\hline Very Good (\%) & 12.8 & 26.7 & 20.8 & 34.1 \\
\hline Good (\%) & 33.0 & 29.0 & 29.3 & 28.3 \\
\hline Fair (\%) & 35.3 & 16.8 & 25.6 & 9.6 \\
\hline Poor (\%) & 10.3 & 11.7 & 17.6 & 2.9 \\
\hline
\end{tabular}

${ }^{\mathrm{a}}$ Excludes dialysis patients

${ }^{b}$ Includes breast, colon \& lung cancers

${ }^{c}$ Excludes CKD, cancer and/or stroke. The condition categories are mutually exclusive

dBased on the ratio of family income to family size and composition: poor $=$ less than $100 \%$ to the poverty line, near poor $=100 \%-125 \%$ of the poverty line, low

income $=125 \%$-less than $200 \%$ of the poverty line, middle income $=200 \%$ - less than $400 \%$ of the poverty line, and high income $=\geq 400 \%$ of the poverty line 
Table 3 Prevalence of comorbidities among U.S. adults aged 21years or older by conditions, years 2011-2013

\begin{tabular}{lcccc}
\hline Comorbidity & CKD $^{\text {a }}$ & Cancer $^{\text {b }}$ & Stroke & No CKD, cancer or stroke $^{c}$ \\
\hline Angina (\%) & 10.3 & 5.9 & 12.6 & 2.3 \\
Arthritis (\%) & 63.7 & 55.2 & 61.2 & 25.8 \\
Asthma (\%) & 11.8 & 14.7 & 11.8 & 9.3 \\
Coronary Heart Disease (\%) & 20.8 & 12.7 & 26.6 & 5.3 \\
High Cholesterol (\%) & 85.0 & 56.2 & 66.8 & 31.5 \\
Diabetes (\%) & 49.6 & 19.3 & 31.2 & 9.3 \\
Emphysema (\%) & 1.2 & 10.7 & 7.8 & 2.0 \\
High Blood Pressure (\%) & 87.8 & 60.9 & 78.2 & 33.8 \\
Heart Attack (\%) & 4.9 & 8.9 & 22.6 & 3.5 \\
Other Heart Disease (\%) & 41.5 & 24.3 & 34.4 & 10.7
\end{tabular}

${ }^{a}$ Excludes dialysis patients

${ }^{b}$ Includes breast, colon \& lung cancers

'Excludes CKD, cancer and/or stroke. The condition categories are mutually exclusive

CKD was 7.2, comparatively higher than the annual outof-pocket health care expenditure burden for the other groups.

After adjusting for demographic variables and comorbidities, CKD, cancer and stroke were associated with significantly higher direct and out-of-pocket expenditures compared to the population without CKD, cancer or stroke. The highest difference in direct expenditures was noted in the group with cancer with $\$ 8608$ (95\% CI \$6167-\$11,049) higher total direct healthcare expenditures relative to population without $\mathrm{CKD}$, cancer or stroke after adjustment for demographics and comorbidities. The highest difference in out-of-pocket expenditures was noted in the group with CKD with $\$ 760$ (95\% CI 0-\$1745) higher out-of-pocket spending relative to population without CKD, cancer or stroke after adjustment for demographics and co-morbidities (Table 5). In contrast, stroke was associated with \$5992 (95\% CI \$4208-\$7775) higher total direct healthcare expenditures and \$246 (95\% CI \$87-\$406) higher out-of-pocket expenditures relative to the group without CKD, cancer or stroke (Table 5).

Table 4 Annual total direct and out-of-pocket healthcare expenditures (in \$2013 US) of U.S. adults aged 21years or older by conditions, years 2011-2013

\begin{tabular}{lll}
\hline & $\begin{array}{l}\text { Total direct } \\
\text { expenditures (\$) } \\
\text { Median (IQR) }\end{array}$ & $\begin{array}{l}\text { Out-of-pocket } \\
\text { expenditures (\$) } \\
\text { Median (IQR) }\end{array}$ \\
\hline CKD $^{\text {a }}$ & $12,877(5031-19,710)$ & $1439(688-2732)$ \\
Cancer $^{\text {b }}$ & $7428(3460-18,323)$ & $770(349-1703)$ \\
Stroke & $8150(3966-19,375)$ & $748(242-1599)$ \\
$\begin{array}{l}\text { Population without CKD, } \\
\text { cancer or stroke }^{c}\end{array}$ & $\$ 1189(196-4388)$ & $226(20-764)$ \\
\hline
\end{tabular}

${ }^{a}$ Excludes dialysis patients; CKD, Chronic kidney disease

${ }^{b}$ Includes breast, colon \& lung

${ }^{c}$ Excludes CKD, cancer and/or stroke. Condition categories are mutually exclusive

\section{Discussion}

This study showed that adults with diagnosed nondialysis dependent CKD based on 585 ICD9 codes had higher total direct and higher out-of-pocket healthcare expenditures compared to adults with stroke or cancer. Our analyses included adults from all stages of CKD including early, moderate, and advanced stages, who were aware of their condition or actively seeking treatment. We chose to compare non-dialysis dependent CKD healthcare expenditures with those for cancer and stroke due to the fact that these chronic conditions are among the most common, costly, and preventable chronic conditions in the U.S [18]. The adjusted out-of-pocket cost burden for the group with CKD was substantially higher compared to the out-of-pocket cost burden for adults without CKD, cancer or stroke.

Our findings were similar to a previous study that examined the annual total expenditures for year 2011 for patients with both CKD and diabetes [15]. However, CKD ascertainment was different between the two studies. In our study, we used the MPC files and associated ICD9 codes to define current conditions including the presence of CKD. In the Ozieh et al. article [15], respondents were identified as having CKD if they responded yes to the question "Has diabetes caused kidney problems?", while diabetes was ascertained by answering yes to the question: "Have you ever been told by a doctor or health professional that you had diabetes?"

Progression of non-dialysis CKD is known to be associated with escalating healthcare costs $[6,8,22]$. In an a analysis of 83,705 adults with type 2 diabetes enrolled in a Medicare Advantage plan, Stage 4 CKD was associated with an incremental cost increase of $\$ 33,131$ relative to stage 1 or no CKD in the $98^{\text {th }}$ percentile of total costs [22]. In a study of Medicare enrollees, CKD was estimated to increase the average Medicare payment for part A by a factor of 12.1 and for part B by a factor of 


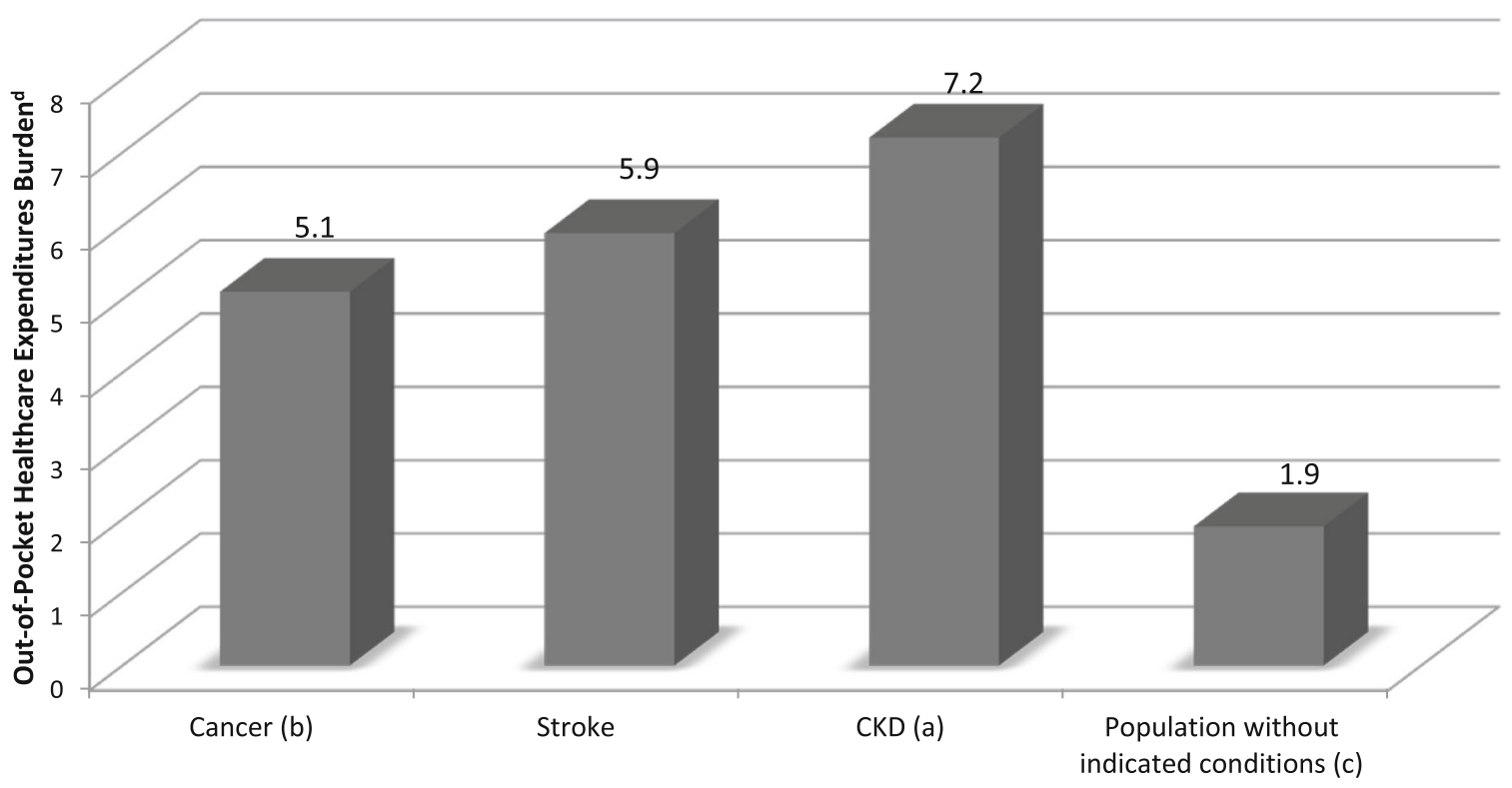

${ }^{\text {a }}$ Excludes dialysis patients

b Includes breast, colon \& lung

${ }^{\mathrm{c}}$ Excludes $\mathrm{CKD}$, cancer and/or stroke. The CKD, cancer, and stroke conditions are mutually exclusive

${ }^{\mathrm{d}}$ Out-of-pocket expenditures burden was calculated as the ratio of out-of-pocket spending to personal income

Fig. 1 Mean out-of-pocket health care expenditures burden of U.S. adults aged 21 years or older by condition categories, years 2011-2013

4.4 among men. Somewhat lower estimates were noted for female enrollees [18]. However, individuals receiving dialysis were not excluded. Previous studies did not examine out of pocket expenditures and associated out of pocket burden. Our study suggests that out of pocket healthcare expenditures for adults with non-dialysis dependent CKD may be higher than those for adults with cancer or stroke and lead to a higher financial burden for individual patients. These findings add to a growing body of literature that confirms the strong financial burden of healthcare costs for patients with
CKD. The higher costs for CKD also hold public health significance because prevalence of CKD is increasing among Medicare Part A beneficiaries, while prevalence of stroke and many cancers are decreasing [9].

The unadjusted higher total healthcare expenditures for CKD may be due to the higher number of comorbidities in this group. The group with CKD defined by 585 ICD 9 codes had the highest prevalence of high cholesterol, diabetes, and high blood pressure. Higher number of co-morbidities is associated with higher number of physician visits and medications utilized as

Table 5 Adjusted differences in total direct and out-of-pocket health care expenditures (in \$2013 US) of U.S. adults aged 21years or older by conditions, years 2011-2013

\begin{tabular}{|c|c|c|c|c|c|c|}
\hline \multirow[b]{2}{*}{ No CKD, cancer or stroke ${ }^{c}$} & \multicolumn{3}{|c|}{${ }^{\mathrm{d}}$ Differences in total direct healthcare expenditures $(\$)$} & \multicolumn{3}{|c|}{${ }^{\mathrm{d}}$ Differences in out-of-pocket expenditures $(\$)$} \\
\hline & Referent & $95 \% \mathrm{Cl}$ & P-value & Referent & $95 \% \mathrm{Cl}$ & P-value \\
\hline $\mathrm{CKD}^{\mathrm{a}}$ & $\$ 4746$ & $\$ 1775-\$ 7718$ & 0.002 & $\$ 760$ & $0-1745$ & 0.130 \\
\hline Cancer $^{\mathrm{b}}$ & $\$ 8608$ & $\$ 6167-\$ 11,049$ & $<0.001$ & $\$ 419$ & $\$ 158-\$ 679$ & 0.002 \\
\hline Stroke & $\$ 5992$ & $\$ 4208-\$ 7775$ & $<0.001$ & $\$ 246$ & $\$ 87-\$ 406$ & 0.002 \\
\hline
\end{tabular}

${ }^{a}$ Excludes dialysis patients; CKD, chronic kidney disease

Includes breast, colon \& lung

'Excludes CKD, cancer and/or stroke. The condition categories are mutually exclusive

${ }^{\mathrm{d}}$ Analysis compares expenditure per chronic condition category, adjusted for the variables listed and race/ethnicity, age, health insurance, gender, poverty status and presence of other co-occurring physical conditions and all costs were inflated to 2013 dollars 
documented in previous studies $[8,11,15]$. In fact, the majority of adults with moderate to severe CKD may have 3 or more co-morbid conditions and take at least 5 medications [11]. The unadjusted median total and out-of-pocket healthcare expenditures of respondents with CKD were substantially larger than expenditures for respondents with cancer and stroke. However, total direct healthcare expenditures decreased and became more comparable to those for stroke and cancer after adjusting for demographic variables and comorbidities. The out-of-pocket expenditures remained higher in the CKD group.

Results from our study are generalizable to adults who are aware of their conditions or who visited a healthcare provider for the condition during the study period. Our CKD sample is therefore, not representative of all U.S. adults with CKD, because the majority with CKD remain unaware of their condition [23].

The strengths of this study included the use of a nationally representative survey of U.S. healthcare expenditures and MEPS data are weighted so that expenditure estimates for a given condition reflect expenditures for the total U.S. population with that condition. However, as noted earlier, presence of conditions in MEPS are based on self-report and rely on accurate recollection by respondents. Also, records in the MEPS Conditions File correspond to current conditions; meaning, the respondent reported the condition as the reason for a particular medical event such as an outpatient visit, the reason for one or more episodes of disability days, or 'bothering' the person during the reference period., The number of sampled persons with non-dialysis dependent CKD with 585 ICD9 codes was small and confidence intervals for the healthcare expenditure estimates were wider than the estimates for the other conditions. Therefore, results from our study should be interpreted in light of the small number of respondents with non-dialysis dependent CKD included in the analyses. The MEPS is representative of the U.S. population and our findings may not be generalizable to non-U.S. populations. Differences in out-of-pocket expenditures for this group relative to the group without CKD, cancer or stroke included zero, which may have been due to the small sample size. Because many adults with CKD remain unaware of their condition, the results from this study do not reflect healthcare expenditures for all U.S. adults with CKD.

\section{Conclusions}

In conclusion, our findings in adults with diagnosed CKD showed that CKD was associated with both high total and out of pocket healthcare expenditures in the U.S. and these expenditures were similar to those of other costly chronic diseases, namely cancer and stroke. Future research should examine interventions for preventing the onset or progression of CKD and reducing the out-ofpocket expenditure burden for adults with CKD.

\section{Additional file}

Additional file 1: Relevant Stata commands used in the study available in a Stata commands 'do' file. (DO $12 \mathrm{~kb}$ )

\section{Abbreviations}

BMI: Body mass index; CCC: Clinical classification codes; CKD: Chronic kidney disease; ICD-9-CM: International classification of diseases, $9^{\text {th }}$ Edition, clinical modification; MEPS: Medical expenditures panel survey

\section{Acknowledgements}

Not Applicable.

Funding

No funding was received to conduct this study.

\section{Availability of data and materials}

The data used in this study is publicly available for scientists from the Agency for Healthcare Research and Quality's (AHRQ) Medical Expenditure Panel Survey (MEPS) website upon MEPS data use agreement. We used the household component full-year and medical conditions files for years 2011, 2012, and 2013 for these analyses. These datasets are downloadable from the following website: https://meps.ahrq.gov/mepsweb/data_stats/ download data files.jsp.

Stata 13 (College Statin, Texas) was used to conduct the analyses; we used the survey [SVY] commands for all analyses and the [glm, fam (gamma) link $(\log )]$ and the [margins, $\left.d y d x\left({ }^{*}\right)\right]$ commands to estimate adjusted total health care expenditures and out-of-pocket spending by the three condition categories compared to the group without CKD, cancer or stroke while simultaneously controlling for race/ethnicity, age, health insurance, gender, poverty status and presence of other co-occurring physical conditions listed in Table 3 (excluding other heart disease). For example, the following Stata command was used to estimate the adjusted differences in total direct health care expenditures by conditions. Please note that some of the variables in the equation were recoded or created by our research team using the descriptions in the methods section and are not directly available from the original dataset. For example, the multi variable in the command indicates that the respondent has more than one of the studied conditions CKD, cancer and stroke simultaneously.

svy: glm TOTEXP i.racerecode i.age i.stroke i.cancer i.CKD i.SEX i.INSCOV i.angina i.arthritis i.asthma i.coronaryheart i.highcholesterol i.diabetes i.emphysema i.highbloodpressure i.heartattack if $A G E>=21$ \& dialysis! $=1$ \& multi==0, fam (gamma) link (log) margins, $d y d x(*)$.

Other relevant Stata commands are provided in Additional file 1.

\section{Authors' contributions}

All the authors made substantive intellectual contributions in this study. CS, HK, and TM made substantial contributions to conception and design, acquisition of data, analysis and interpretation of data, drafting the manuscript and revising it critically for important intellectual content. KG, KV, DL, VB made substantial contributions to interpretation of data and revising it critically for important intellectual content. All the authors have given final approval of the version to be published and they have participated sufficiently in the work to take public responsibility for appropriate portions of the content.

\section{Competing interests}

KG has lab funding with Complexa Company but no other financial or non-financial competing interests. The other authors declare that they have no financial or non-financial competing interests.

Data from this study was presented at AcademyHealth/Agency for Healthcare Research and Quality (AHRQ) Annual Conference, Crystal City, Virginia on October 2015 and at the American Society of Nephrology meeting, November 2015, San Diego, CA.

Consent for publication

Not applicable.

Ethics approval and consent to participate

The Loyola University Medical Center Institutional Review Board approved the study, which used publicly available data from the Agency for Healthcare 
Research and Quality's (AHRQ) Medical Expenditure Panel Survey (MEPS). All information for MEPS is collected with assurances of confidentiality, and individual identifiers have been removed from the micro data contained in these files. Nevertheless, by using these data, the authors signified their agreement to comply with the MEPS data use agreement. Therefore, consent to participate was not collected by the authors in this study. The 'Data Use Agreement' for MEPS could be found on the following website, section A. https://meps.ahrq.gov/data_stats/download_data/pufs/h163/ h163doc.shtml.

\section{Author details}

'Department of Public Health Sciences, Loyola University Chicago, 2160 S. First Ave, Maywood, IL 60153, USA. ²Division of Nephrology and Hypertension, Loyola University Medical Center, Maywood, IL, USA. ${ }^{3}$ Hines Veterans Affairs Medical Center, Hines, IL, USA.

\section{Received: 25 August 2016 Accepted: 21 December 2016}

Published online: 05 January 2017

\section{References}

1. Levey AS, Stevens LA, Schmid CH, Zhang YL, Castro 3rd AF, Feldman HI, Kusek JW, Eggers P, Van Lente F, Greene T, Coresh J, CKD-EPI (Chronic Kidney Disease Epidemiology Collaboration). A new equation to estimate glomerular filtration rate. Ann Intern Med. 2009;150(9):604-12.

2. Murray CJ, Atkinson C, Bhalla K, Birbeck G, Burstein R, Chou D, Dellavalle R, Danaei G, Ezzati M, Fahimi A, Flaxman D, Foreman, Gabriel S, Gakidou E, Kassebaum N, Khatibzadeh S, Lim S, Lipshultz SE, London S, Lopez, Maclntyre MF, Mokdad AH, Moran A, Moran AE, Mozaffarian D, Murphy T, Naghavi M, Pope C, Roberts T, Salomon J, Schwebel DC, Shahraz S, Sleet DA, Murray, Abraham J, Ali MK, Atkinson C, Bartels DH, Bhalla K, Birbeck G, Burstein R, Chen H, Criqui MH, Dahodwala, Jarlais, Ding EL, Dorsey ER, Ebel BE, Ezzati M, Fahami, Flaxman S, Flaxman AD, Gonzalez-Medina D, Grant B, Hagan H, Hoffman H, Kassebaum N, Khatibzadeh S, Leasher JL, Lin J, Lipshultz SE, Lozano R, Lu Y, Mallinger L, McDermott MM, Micha R, Miller TR, Mokdad AA, Mokdad AH, Mozaffarian D, Naghavi M, Narayan KM, Omer SB, Pelizzari PM, Phillips D, Ranganathan D, Rivara FP, Roberts T, Sampson U, Sanman E, Sapkota A, Schwebel DC, Sharaz S, Shivakoti R, Singh GM, Singh D, Tavakkoli M, Towbin JA, Wilkinson JD, Zabetian A, Murray, Abraham J, Ali MK, Alvardo M, Atkinson C, Baddour LM, Benjamin EJ, Bhalla K, Birbeck G, Bolliger I, Burstein R, Carnahan E, Chou D, Chugh SS, Cohen A, Colson KE, Cooper LT, Couser W, Criqui MH, Dabhadkar KC, Dellavalle RP, Jarlais, Dicker D, Dorsey ER, Duber H, Ebel BE, Engell RE, Ezzati M, Felson DT, Finucane MM, Flaxman S, Flaxman AD, Fleming T, Foreman, Forouzanfar MH, Freedman G, Freeman MK, Gakidou E, Gillum RF, Gonzalez-Medina D, Gosselin R, Gutierrez HR, Hagan H, Havmoeller R, Hoffman H, Jacobsen KH, James SL, Jasrasaria R, Jayarman S, Johns N, Kassebaum N, Khatibzadeh S, Lan Q, Leasher JL, Lim S, Lipshultz SE, London S, Lopez, Lozano R, Lu Y, Mallinger L, Meltzer M, Mensah GA, Michaud C, Miller TR, Mock C, Moffitt TE, Mokdad AA, Mokdad AH, Moran A, Naghavi M, Narayan KM, Nelson RG, Olives C, Omer SB, Ortblad K, Ostro B, Pelizzari PM, Phillips D, Raju M, Razavi H, Ritz B, Roberts T, Sacco RL, Salomon J, Sampson U, Schwebel DC, Shahraz S, Shibuya K, Silberberg D, Singh JA, Steenland K, Taylor JA, Thurston GD, Vavilala MS, Vos T, Wagner GR, Weinstock MA, Weisskopf MG, Wulf S, Murray, U.S. Burden of Disease Collaborators. The state of US health, 1990-2010: burden of diseases, injuries, and risk factors. JAMA. 2013, 310(6):591-608.

3. Anonymous. Centers for Disease Control and Prevention. Chronic Kidney Disease Surveillance System-United States. http://www.cdc.gov/ckd. Accessed 2 July 2016.

4. Grams ME, Chow EK, Segev DL, Coresh J. Lifetime incidence of CKD stages 3-5 in the United States. Am J Kidney Dis. 2013;62(2):245-52.

5. Anonymous. United States Renal Data System Annual Data Report 2014 Chapter 2: Identification and Care of Patients with Chronic Kidney Disease. https://www.usrds.org/2014/download/N1_Ch_02_Care-and-ID-of-CKDPatients.pdf. Accessed 2 July 2016.

6. Honeycutt AA, Segel JE, Zhuo X, Hoerger TJ, Imai K, Williams D. Medical costs of CKD in the Medicare population. J Am Soc Nephrol. 2013;24(9):1478-83.

7. Braun L, Sood V, Hogue S, Lieberman B, Copley-Merriman C. High burden and unmet patient needs in chronic kidney disease. Int J Nephrol Renovasc Dis. 2012;5:151-63.
8. Wang V, Vilme H, Maciejewski ML, Boulware LE. The economic burden of chronic kidney disease and end-stage renal disease. Semin Nephrol. 2016;36(4):319-30

9. Erdem E. Prevalence of chronic conditions among Medicare Part A beneficiaries in 2008 and 2010: are Medicare beneficiaries getting sicker? Prev Chronic Dis. 2014;11:130118.

10. Anonymous. Centers for Medicare and Medicaid Services. Chronic conditions among Medicare beneficiaries, chartbook. Baltimore: U.S. Department of Health and Human Services; 2012.

11. Fraser S, Roderick P, May C, McIntyre N, Mcintyre C, Fluck R, Shardlow A, Taal M. The burden of comorbidity in people with chronic kdieny disease stage 3: A cohort study. BMC Nephrol. 2015;16(1):193.

12. Soni A, Wright J. Average annual health care use and expenditures for kidney disease among adults 18 and older, U.S. civilian noninstitutionalized population, 2003-2007. Statistical Brief 306. Rockville: Agency for Health Care Research and Quality; 2010. http://www.meps.ahrq.gov/mepsweb/ data_files/publications/st306/stat306.pdf. Accessed 2 July 2016.

13. Anonymous. United States Renal Data System Annual Data Report 2013. Atlas of chronic kidney disease in the United States, National Institutes of Health, National Institute of Diabetes and Digestive and Kidney Diseases, Bethesda, MD. 2013.

14. Schneider K, O'Donnell BE, Dean D. Prevalence of multiple chronic conditions in the United States' Medicare population. Health Qual Life Outcomes. 2009;7:82.

15. Ozieh MN, Dismuke CE, Lynch CP, Egede LE. Medical care expenditures associated with chronic kidney disease in adults with diabetes: United States 2011. Diabetes Res Clin Pract. 2015;109(1):185-90.

16. Roggeri A, Roggeri DP, Zocchetti C, Bersani M, Conte F, ReNe (Renal Lombardy Network), Additional contributors from ReNe Network. Healthcare costs of the progression of chronic kidney disease and different dialysis techniques estimated through administrative database analysis. J Nephrol. 2016 May 10. [Epub ahead of print]

17. Kaiser Family Foundation, Kaiser Health Tracking Poll: Public Opinion on Healthcare Issues. 2009. http://kaiserfamilyfoundation.files.wordpress.com/ 2013/01/7891.pdf. Accessed 1 Nov 2016.

18. Erdem E, Prada SI, Haffer SC. Medicare payments: how much do chronic conditions matter? Medicare Medicaid Res Rev. 2013, 3(2). doi:10.5600/ mmrr.003.02.b02. eCollection 2013.

19. Meraya AM, Raval AD, Sambamoorthi U. Chronic condition combinations and health care expenditures and out-of-pocket spending burden among adults, Medical Expenditure Panel Survey, 2009 and 2011. Prev Chronic Dis. 2015;12:E12.

20. Manning WG, Mullahy J. Estimating log models: To transform or not to transform? J Health Econ. 2001;20(4):461-94.

21. Hardin J, Hilbe J. Generalized linear models and extensions. 2nd ed. College Station, Texas: Stata Press; 2007.

22. Slabaugh SL, Curtis BH, Clore G, Fu H, Schuster DP. Factors associated with increased healthcare costs in Medicare Advantage patients with type 2 diabetes enrolled in a large representative health insurance plan in the US. J Med Econ. 2015;18(2):106-12.

23. Plantinga $L C$, Boulware $L E$, Coresh J, Stevens LA, Miller 3rd ER, Saran R, Messer KL, Levey AS, Powe NR. Patient awareness of chronic kidney disease: trends and predictors. Arch Intern Med. 2008;168(20):2268-75.

\section{Submit your next manuscript to BioMed Central and we will help you at every step:}

- We accept pre-submission inquiries

- Our selector tool helps you to find the most relevant journal

- We provide round the clock customer support

- Convenient online submission

- Thorough peer review

- Inclusion in PubMed and all major indexing services

- Maximum visibility for your research

Submit your manuscript at www.biomedcentral.com/submit
Biomed Central 